\title{
A New Perspective on Pragmatic Functions of Discourse Markers
}

\author{
Zhi-de Hou \\ Shenzhen Tourism College of Jinan University, Shenzhen, Guangdong, China
}

\begin{abstract}
As a common linguistic phenomenon in both English and Chinese conversations, discourse markers are parts of information organization in discourse analysis. In conversational communication, the pragmatic function of discourse markers was analyzed under the framework of Relevance Theory for its procedural constraints and speakers' attitude. In addition, the tentative analysis of conceptual information and truth condition of discourse markers provided a new perspective in discourse analysis.
\end{abstract}

Keywords - Relevance, Discourse markers, pragmatic function, procedural constraint, conceptual information, truth condition

\section{话语标记语的语用功能研究新视角}

\author{
侯智德 \\ 暨南大学深圳旅游学院, 深圳, 广东, 中国
}

摘 要 话语标记语是话语信息组织的一部分。英汉语会话应对中话语标记语这一语言现象普遍存在。在言语交际中, 关联理 论可以解释话语标记语对话语理解的语用功能: 程序制约功能和表达说话人态度。针对有些话语标记语本身所体现的概念信息及它 们对话语真值条件影响的试探分析为话语标记语的语用功能研究提供了新视角。

关键词 矢联；话语标记语；语用功能；语用制约；概念信息；真值条件

1. 引言

话语标记语是指话语元语言层面上的, 用以指引听话 人的具有语用意义的简短词项。话语标记语是话语信息组 织的一部分, 从局部或整体上对话语的建构与理解产生语 用制约性, 具有动态的语用特征 (何自然, 苒永平 1999）。关联理论认为, 话语标记语的使用就是为了保证 听话人能正确地理解话语, 并付出尽可能少的努力, 这就 从认知上指出了话语标记语这类语言机制存在的理据。

言语交际涉及说话人与听话人对信息的处理。根据关联 理论, 说话人通过明示交际行为, 让听话人获取某种信 息; 听话人则通过语言解码和推理, 获取说话人的交际意 图, 这就是关联理论中的明示一推理交际模式。因此, 对 说话人来说是明示的言语行为, 即说话人会制约听话人对 话语关联性的寻找, 而听话人就要努力寻找话语与语境假 设之间的关联, 进行推理, 从而获取说话人所期待的话语 理解。由于在言语交际中, 话语标记语可以帮助听话人对 话语的理解, 使听话人更容易地寻找话语的关联性, 从而 减少话语理解时付出的认知努力。本文将以关联理论为基
础, 通过英汉语的会话应对语料分析, 旨在论证话语标记 语对话语理解的语用功能, 同时也对话语标记语本身所体 现的概念信息及它们对话语真值条件的影响进行试探研 究。

\section{2. 话语标记语与最佳关联}

在言语交际中, 关联性是成功交际的基本前提。相关 话语的信息意图是通过“互显”假设来实现的。当听话人试 图识别言语意图时, 他就进入到了一个明示一推理交际的 过程。对说话人来讲, 交际应是一种将自己要传递某事的 意图明朗化的行为。这种明示行为将触发一定的认知环境 或语境, 即交际双方对交际聚集点的共识, 这种认知环境 是交际场合里物理环境和交际双方认知能力的函数（熊学 亮 2003）。说话人必须首先对听话人的认知资源做出合 适的估计, 然后再选用恰当的话语方式或结构, 话语标记 语的实施就能充当制约话语理解的作用。说话人要考虑自 己所需付出的努力, 要考虑礼仪、伦理因素, 还要受自己 能力的限制。总之, 该明示性刺激信号是说话人能力和意 
愿所允许的关联性最大的信号。这种考虑到说话人利益的 最大关联性, 在说话人能力和意愿允许范围内的最大关联 性, 就是Sperber \& Wilson（1986/1995: 270）所说的“最佳 关联性”。于是, 说话人就可以通过某一特定的语言手段 来制约听话人对话语的理解。话语标记语就能充当这一角 色。在研究话语理解的过程中, Blakemore举了下例:

(1) Barbara is in town. David isn't here.

在这两句话语中, 说话人可以通过音调或话语标记语 来制约对第二个句子的理解, 说话人可使用诸如 so, after all, moreover, however 等话语标记语, 制约话语的理解。 所以, 在言语交际中, 话语标记语可以使话语更具最佳关 联性, 即说话人的最佳关联性充分解释了话语标记语的语 用功能。

在言语交际中, 听话人知道说话人并不会总是说出最 佳关联的话语, 因为说话人不能说出他不知道的话, 也不 能说出他不能说的话（譬如由于宗教、合法性等问题）。 同时, 说话人并非总是以非常友好的方式说话, 这也正如 Sperber \& Wilson所说的, 说话人受到他的能力和喜好制 约。据此, 听话人就能期待说话人发出与其能力及偏爱相 一致, 具有最佳关联性的话语。在本研究中, 我们不考虑 说话人的能力和喜好会影响话语关联的程度, 并且认为说 话人总是说出对听话人来说最佳关联的话语。那么, 在会 话应对中说话人是如何运用话语标记语来体现他的能力和 喜好的呢? 请看下例:

\section{(2) A: Did you kill your wife?}

B: Well, yes.

在听话人看来, 话语标记语 well 似乎并不关联, 但如 果考虑说话人的喜好, well就是关联的（譬如说话人想证 实自己并非冷漠的杀人狂）。于是听话人就会获得说话人 直言 (如回答“yes”) 所不能获得的效果。据此, 说话人实 施话语标记语well表明了其话语是受能力和喜好制约的。

\section{3. 话语标记语的认知语用功能}

关联理论学者Blakemore (1987，1990) 在解释话语 标记语, 诸如英语中的so, after all, but 等时, 率先提出了 话语标记语对信息处理的程序制约作用。她认为, 它们表 示的是话语之间或话语与语境之间的一种关系, 这种关系 在处理话语的命题意义、语义信息时起语用制约作用, 这 就是程序信息。因此, 在话语理解时, 话语标记语所包含 的程序信息通过表达的语义关系, 引导听话人理解话语, 为话语信息处理提供一种认知方向, 从而对话语理解起制 约作用, 以减少听话人话语理解时所付出的努力, 增加话 语理解成功的机会。话语标记语的程序制约作用表现在两 个方面：（1）对推导话语所表征的语义信息直接进行制
约; (2) 对话语理解所需要的语境进行制约, 即程序信 息会影响话语理解时的语境构建。如:

(3) A：以前我俩的关系很好, 他经常晚上, 一般两三 天吧, 给我打电话聊天, 一聊就是半个小时......

B：看来, 你们至少有很多话可讲, 谈的来。也就是 说，你们还是很有共同语言。

A: 㕪, 对呀。不过, 我发现后来他给我的电话越来 越 少了, .......

斜体部分即话语标记语表达的是一种语用关系, 它可 以帮助人们识别说话人是如何影响或制约话语之间的信息 关系, 或通过该信息表达说话人的某种认知态度等。具体 地说, “看来”表明其前、后话语之间的一种总结或信息推 导; 在有的情况下还可以表示一种语境推导。“也就是说” 指前后话语所表达的语义信息之间的一种平行关系, 或信 息转陈关系, 其主要认知功能就是通过语言上的明示, 向 听话人暗示话语标记语后面所转陈的话语信息更容易理 解。“不过”的作用就是表明前后话语之间的一种信息对比 关系, 起的是一种语用否定作用。所以, 话语标记语主要 是表示一种关系, 为话语理解提供一个认知方向, 让听话 人沿着它去寻找话语之间或话语与交际情景之间的某种联 系以及话语与认知语境之间的关联性, 从而保证听话人在 付出较小的努力以后, 进行正确的语境选择与恰当的话语 理解。

此外, Andersen 和 Fretheim (2000) 指出研究话语 标记语传递的话语态度意义和主观性无其重要。据此, 实 施话语标记语有助于表现说话人的某种态度。

第一、话语标记语表现说话人的礼貌态度。在言语交 际中说话人和听话人要为维护和谐的人际关系进行种种努 力, 尽量做到有礼貌。礼貌就是通过采取一定的语言手段 达到给对方或自己留有面子。Brown和Levinson（1987） 认为, 很多言语行为都可能威胁面子。因此, 在言语交际 中人们就要选择一定的手段去满足面子的需求, 因为交际 中说话人或者听话人的面子可能会受到一定程度的威胁, 此时就需要人们努力缓和其威胁的力度。话语标记语就是 这样的语言手段, 它的恰当使用可以起到调节人际关系的 作用, 表现说话人的礼貌态度。

言语交际中经常会出现这样的情况, 当说话人和听话 人之间的意见或看法出现对立, 或说话人的请求遭到拒 绝等。类似情况的出现意味着说话人或听话人的面子会受 到威 胁, 这样的言语行为就是威胁面子的行为。例如:

(4) A: We'll all miss Bill and Agatha, won't we?

B1: Well, we'll miss Bill.

B2: We'll miss Bill. 
此例中, B1借助话语标记语well 回答了提问的部分 内容, 即肯定想念Bill一人, 而不提及自己不喜欢的 Agatha, 这样就给对方留有面子, 而B2却显得较为生硬且 威胁对方的面子。使用话语标记语well就是为了恪守一定 的礼貌原则, 使对方更容易接受自己的观点或看法, 以达 到礼貌待人的效果。虽然话语标记语并非在句子结构上制 约话语, 但没有它话语似乎显得太唐突。因此, 话语标记 语可以缓和语气, 以示礼貌。

第二, 话语标记语表现说话人的讽刺态度。说话人在 话语中实施话语标记语以引导听话人对话语的理解, 但听 话人却获得与说话人意愿相反的或有讽刺意义的理解。于 是, 说话人借助话语标记语可以表达讽刺的言语意图。例 如: (5) This is Paul. He is a syntactician, but he's quite intelligent.

当听话人在话语理解的过程中, 一听到话语标记语 but, 其语用否定的功能就会被激活, 这样听话人就会期 待获取最相关的理解: Paul is not intelligent. 但这与说话人 的言语意图正好相反。除非说话人给定的语境假设仅是: No syntactician is intelligent, 听话人就可以让他获得所期 待的话语理解。据此, 说话人可利用话语标记语表现他的 讽刺态度, 上例中话语表现出一种分离的特征, 这样说话 人就有意地表达了他的言语讽刺意图。

\section{4. 话语标记语与真值条件}

真值条件是话语意义的最为基本的部分 (Vogel, 2001）。在Davison (1984)的意义理论里, “真”或“假”是相 对于一个特定说话者和一个特定时间或情景来判断的; 说 话者要能够证明他在特定时间或情景下所描述的事态存 在, 他的话语才是真的。这就是强调话语与其描述的事态 存在着实在的对应关系, 要用这种对应关系判定话语的真 假。正因为是这样, 真值条件意义理论充分地表现出 “真 值条件是意义的最为基本的部分”（徐盛桓 2009）。在言 语交际中, 一般普遍认为话语标记语主要体现它的程序制 约语用功能, 话语标记语本身不含真值条件。持本观点的 学者很多, 如Blakemore (1987, 1990), Fraser (1990), Holker (1991)及国内诸多学者, 他们都明确表示话语标记 语不会给话语的命题内容增加任何信息。这样看来, 话语 标记语可以省略而不致影响话语意义的“真”或“假”。

Wilson \& Sperber (1993) 认为某些话语标记语, 如 I think, I mean, you know, 确实含有概念信息, 但它们的出 现不会影响话语的真值条件。他们认为这些话语标记语起 到以更明确的方式指引听话人获得话语的高阶明示的作 用。在汉语中诸如此类的话语标记语很多, 如“我的意思 是”, “你知道”, “我猜猜”, “我觉得”等都含有概念意义。
但在理解含有此类话语标记语的话语意义时, 当它们能有 效满足我们根据我们的目的对某一情景所作的理解时, 我 们可以在一个给定的情景中认为这些话语标记语为“真”, 亦即他们的出现含影响话语理解的真值条件。试看下例:

（6）张道恒这时忽然古怪地咧开嘴笑了, 眼睛饶有兴 趣地望着前面的戴无遗。“恕我直言, 在很多方面, 你都 还显得很幼稚, 你需要得到一种真正的锻炼。我是说, 你 应该参加“破与立”。这也许是我给你开的一帖最好的药方 了。”这人在说话时眼睛里的目光已从他脸上挪开, 一直 在望着黑洞洞的窗外。“当然, 我并没有任何勉强你的意 思, 但我提出的邀请是诚挚的。从我内心说, 我希望你能 参加。”

以上话语标记语的语用功能都起到缓和说话人的语气 的作用。根据关联理论, 这是说话人喜好的体现。但从命 题内容看, 话语中有无话语标记语, 内容上并不完全等 同。试比较上例中最后一句:

(a)从我内心说, 我希望你能参加。

(b)我希望你能参加。

(a)句表示说话人确确实实希望听话人能参加。但 （b）句说话人就不一定表达真诚的愿望, 说话人既可表 达婉转的意愿, 也可表达轻菻地邀请听话人参加, 甚至还 可以表示正话反说。具体要看说话人当时的语气。所以, 含话语标记语的 (a) 句, 就不仅在语用上制约了听话人 对话语的理解, 也使话语内容本身得到了制约。这样看 来, 话语标记语就含有命题内容, 也就起到了影响话语理 解的真值条件的作用。因为这个话语标记语能有效满足我 们根据我们的目的对这一情景做出理解。真值条件是话语 意义的最为基本的部分。具体来说, 即话语的意义与话语 (的命题) 真值至为相关, 陈述一个话语的真值条件便能 认定话语的意义。当话语标记语限定了话语的意义, 话语 标记语的真值条件就显现出来了。

\section{5. 结论}

本文以关联理论为框架, 探讨了话语标记语的语用功 能。在认知上, 话语标记语可从局部或整体上对话语理解 起着引导或路标的功能, 帮助听话人识别话语的各种语用 关系, 从而在认知上对话语理解进行制约。这是话语标记 语的程序制约语用功能。同时, 话语标记语也表达说话人 的话语态度。正如很多关联理论学者所指出的那样, 话语 标记语主要是在语用上对话语理解起制约作用, 但我们也 不能忽略话语标记语所具有的显而易见的概念信息及它们 对话语真值条件的影响。笔者在本文中进行了试探性研 究, 旨在进一步探讨话语标记语的语用功能。 


\section{参考文献(References)}

[1] Andersen, Gisle \& Thorstein Fretheim (eds) Pragmatic Markers and Propositional Attitude. Amsterdam: John Benjamins, 2000.

[2] Brown, P. \& S. Levinson. Politeness: Some Universals in Language Usage. Cambridge: Cambridge University Press, 1987.

[3] Davison, D. Truth and Meaning. In D. Davison (ed.). Inquiring into Truth and Interpretation. Oxford: OUP. 1984: 17-42.

[4] Fraser, Bruce. An approach to discourse markers. Journal of Pragmatics 1990(14): 383-395.

[5] Holker, Klaus. Franzosisch: Partikelforschung. Lexikon der Romanistischen Linguistic 1991, Vol. 1: 77-88.
[6] Sperber, D. \& D. Wilson. Relevance: Communication and Cognition . Oxford: Blackwell, 1986/1995.

[7] Wilson, Deirdre \& Dan Sperber. Linguistic Form and Relevance. Lingua 1993, 90: 1-25.

[8] Vogel, C. Dynamic semantics for metaphor. 2001, http://www.cs.tcd.ie/research_group/clg/metaphorsymbol01.pdf

[9] He, Ziran \& Ran, Yongping. Pragmatic constraints of discourse connectives. Foreign Language Teaching and Research 1999, Vol. 3.

[10] Xiong, Xueliang. New Perspectives of Linguistics. Shanghai: Fudan University Press, 2003. 